\title{
THE UNIFIED ENTERPRISE ARCHITECTURE (AEU) AS A STRATEGIC TOOL ORGANIZATIONAL MODELING FOR THE FUNTIONAL COMPETITIVENESS OF UNIVERSITIES
}

Oswaldo Alfaro Bernedo

National University Federico Villarreal, (Perú).

E-mail: oalfaro@unfv.edu.pe ORCID: https://orcid.org/0000-0002-9803-5986

Doris Esenarro

National University Federico Villarreal, (Perú). E-mail: desenarro@unfv.edu.pe ORCID: https://orcid.org/0000-0002-7186-9614

Giro Rodriguez

National University Mayor de San Marcos, (Perú). E-mail: crodriguezro@unmsm.edu.pe ORCID: https://orcid.org/0000-0003-2112-1349

Maria René Alfaro

National University Federico Villarreal, (Perú). E-mail: mralfaro@unfv.edu.pe ORCID: https://orcid.org/0000-0003-4601-6748

Citación sugerida Suggested citation

Alfaro, O., Esenarro, D., Rodriguez, C., y Alfaro, M. R. (2021). The Unified Enterprise Architecture (AEU) as a strategic tool organizational modeling for the funtional competitiveness of universities. 3C Empresa. Investigación y pensamiento crítico. Edición Especial Tourism and University: Backbone of Peruvian Economy, 63-79. https://doi.org/10.17993/3cemp.2021.specialissue1.63-79 


\section{ABSTRACT}

This research work proposes the design and application of an organizational model based on two very important and well-known precedents: On the one hand, the so-called Enterprise Architecture (EA), as a powerful methodology of business modeling based on Zachaman's Framework and, on the other hand, the Unified Process of Rational (UPR), so that together they achieve a synergistic merger, giving rise to the so-called Unified Enterprise Architecture (UEA), in order to articulate all the perspectives and aspects that are part of the original EA with a third dimension formed by the phases and iterative dynamics of the UPR. In this way, the systemic organizational modeling of universities is very useful; however, its application is valid for all types of organizations. The design of the experimental research of the pre-test and post-test type with a control group is defined, a computer application is developed as a prototype and the empirical test is carried out through direct observation for the control group and simulation for the experimental group; results are evaluated based on the management indicators Efficiency, effectiveness and productivity.

\section{KEYWORDS}

Information technologies, Enterprise architecture, Unified Enterprise Architecture, Unified process of Rational, Simulation. 


\section{INTRODUCTION}

The scenarios in which organizations operate are increasingly complex, demanding greater management capacity to achieve or maintain adequate levels of competitiveness. In this regard, there are evident scientific and technological advances aimed at generating new knowledge, management tools and technological tools; however, such efforts are not articulated in a systemic way, achieving isolated results and, in many cases, contributing to increase the existing complexity. Management methods focused on the organized alignment between business plans, information systems plan and information technology plans are still incipient. In this context, the organizations solve in an incomplete and ineffective way the immediate problems that are manifested in their future, but it is still not considered an integral solution of all the agents that are part of the socio-technical system (Reyes, Rodriguez, \& Esenarro, 2019).

One of the main manifestations of the deficiencies and restrictions derived from the framework of action indicated for the Peruvian public university system in general and, in the UNFV in particular, is the scarce use of modern management tools supported by information technologies to improve the performance of its business processes. The indicators in which the low performance of such processes becomes tangible are efficiency, effectiveness and productivity. Ultimately, the result of this problematic situation is manifested in the provision of administrative services with a low level of competitiveness, even in the national context. Another cause of the low level of performance of administrative processes is the lack of knowledge of management methodologies and tools supported by information technology, which allow the integration of all the functionality of the organization (Bastidas, Helfert, \& Bezbradica, 2018).

Consequently, the objective of this research work is to "establish the degree of influence that the design and application of an organizational model based on the Unified Enterprise Architecture, in the functional competitiveness of universities," understood the Unified Enterprise Architecture as a manifestation of modern business engineering, which aims to integrate all management tools with a coherent technological support, as well as the dynamic and iterative component that gives the third dimension of phases provided by the RUP (Kitsios \& Kamariotou, 2019). 
To prove that the functional competitiveness of the universities improves as a result of this proposed organizational model, the corresponding hypothesis is formulated in the following terms: "If an organizational model based on the Unified Enterprise Architecture is designed and used, then the functional competitiveness of the universities improves". The related independent and dependent variables for this purpose are Organizational model based on the Unified Enterprise Architecture and the functional competitiveness of the universities, respectively; for each of them, indicators have been identified to which a specific metric is applied. In the case of the dependent variable, the indicators are constituted by efficiency, effectiveness and productivity.

\section{METHODOLOGY}

The present research is based on the specific scientific method because of the perfection and effectiveness it has achieved [SIE96] and because its development and improvement are closely linked to the development of technology, since the validity of the hypothesis formulated after data collection is tested (Bastidas et al., 2018).

This research method is framed in the typology of field research thesis, that is, the appropriate method for researches in which information has been collected framed by the specific environment in which the study phenomenon is presented. In the realization of these theses, an exclusive research method is used and certain tools are designed to collect information that are only applied in the environment in which the phenomenon of study acts; for the tabulation and analysis of the information obtained, statistical and mathematical methods and techniques are used that help to obtain formal, scientifically proven conclusions. As specific orientations used, we have the deductive method, the inductive method and the experimental method [CAB99] (Huapaya, Rodriguez, \& Esenarro, 2020).

Consequently, the thesis follows a proven method of collection, tabulation and analysis of the antecedents that have been obtained and proven to be valid directly in the field in which the research fact has been presented.

\subsection{SAMPLE}

The sample selected is of the probabilistic type because any transaction corresponding to the business processes involved has the same opportunity to form the control and 
experimental group. Likewise, this sample is considered to be of the probabilistic type because the execution of such processes can occur at any time, according to the demand of users or the organization itself when faced with environmental requirements.

\subsection{PRESENTATION AND FUNCTIONAL METAMODEL OF THE AEU}

The metamodel of the Unified Enterprise Architecture (AEU) is presented in detail; the same that has been conceived and designed on the basis of the Enterprise Architecture, complementing it with the framework of the Rational Unified Process (RUP). Regarding the latter, the so-called disciplines have been ignored, taking into account that the perspectives contained in the Business Architecture cover these disciplines fairly closely; furthermore, they exceed the breadth of scope, since they cover a greater spectrum of conceptualization of the organizational model to be represented. In this way, the constituent phases of the RUP framework have been associated with the Enterprise Architecture framework, maintaining their iterative nature, a fact that gives a perception of a dynamic process to the construction of such a metamodel. Next, in Figure 1, the metamodel of the Unified Enterprise Architecture (AEU) is presented.

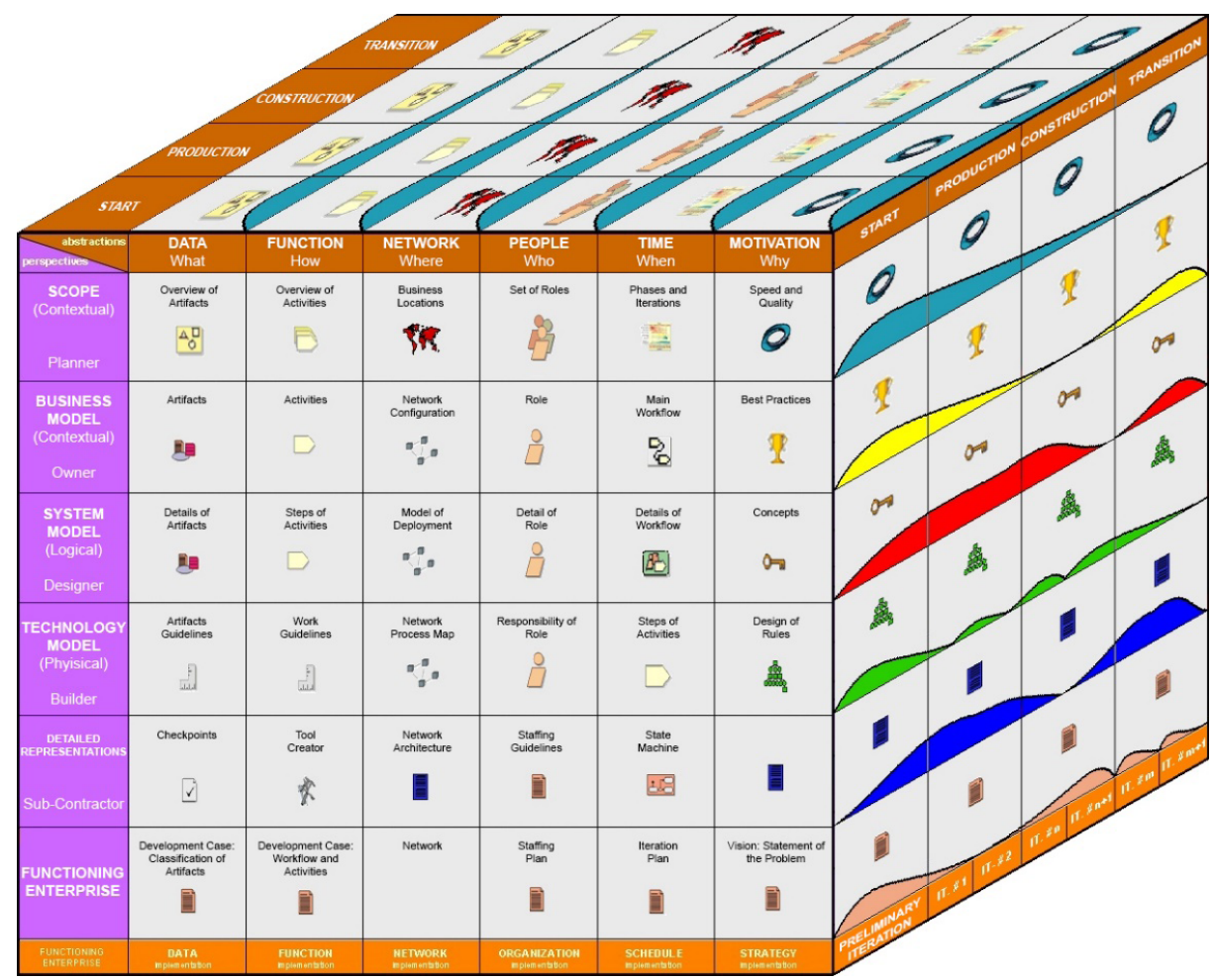

Figure 1. The Unified Enterprise Architecture Metamodel (AEU). 
As can be seen Figure 1, the three dimensions of this metamodel constitute it: six Perspectives, six Aspects and four Phases; the iterative component of the model suggests that the artifacts to be built in each cube should be carried out in as many steps as necessary, depending on the combination of the three dimensions. Therefore, this metacube is made up of 144 finished cubes; however, taking into consideration that the corresponding artifacts (models) resulting from each cube require at least two iterations, it is clear the extent of the functional scope and effort required to achieve the full development of this systemic organizational model.

Once the functional metamodel of the AEU has been represented, the next step is to build the corresponding functional model, that is, following the pattern of the perspectives (for each one of them), to elaborate the corresponding use case diagrams, in such a way that the whole functional scope of the Unified Enterprise Architecture is covered at the highest level of abstraction (Reyes et al., 2019).

\subsubsection{ITERATED OPERATIONAL PERSPECTIVE - 3D}

Figure 2 presents the diagram of business use cases corresponding to the operational perspective, or also called system functionality. This is a view of the system functionality in its operational environment. The business use cases stand out: use data, execute functionality, use the network, implement programming, etc.

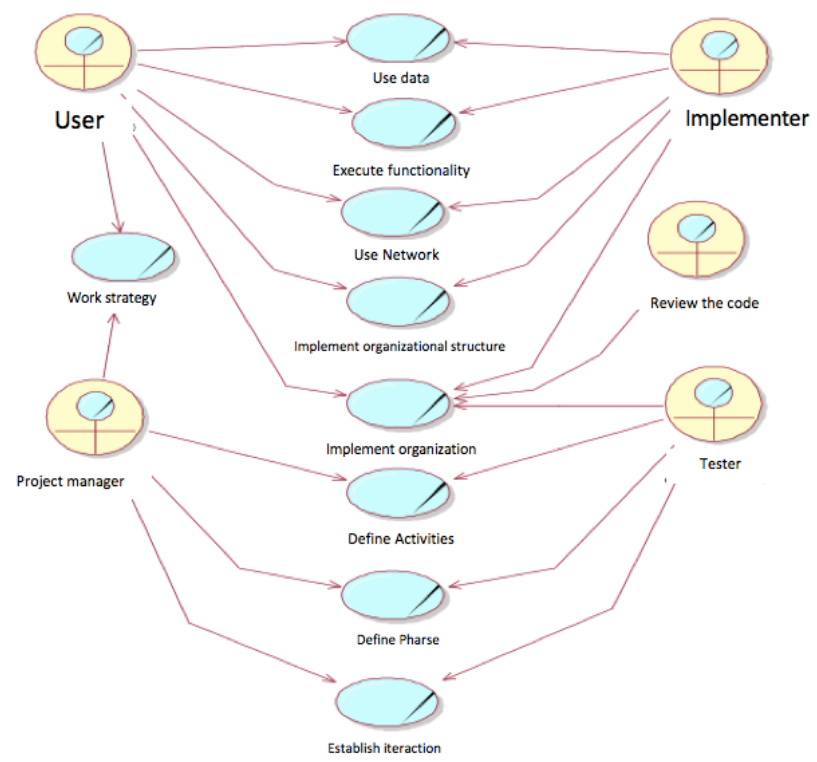

Figure 2. DCU of the Operational perspective Iterada-3D of the AEU. 
Regarding the business actors involved in this perspective, as is obvious, it obeys the need to operationalize all the functionality and details of the system; in addition to the project manager, the user, the implementer, the code reviewer and the tester intervene. (Langermeier, Saad, \& Bauer, 2014).

\subsubsection{AEU METAMODEL LOGIC}

As it can be seen, in this metamodel, it is possible to interpret in an abstract way all the possible models, diagrams, artifacts, activities, etc, that can be derived through the corresponding instantiation process. Such a metamodel covers the whole scope of the AEU (Petar et al., 2019).

The purpose of presenting this model is to map in a holistic way the main objects that are derived from the functionality developed in the previous chapters, as well as the relationships, both in the form of associations, aggregations, generalizations, etc., that are established by the interaction between them.

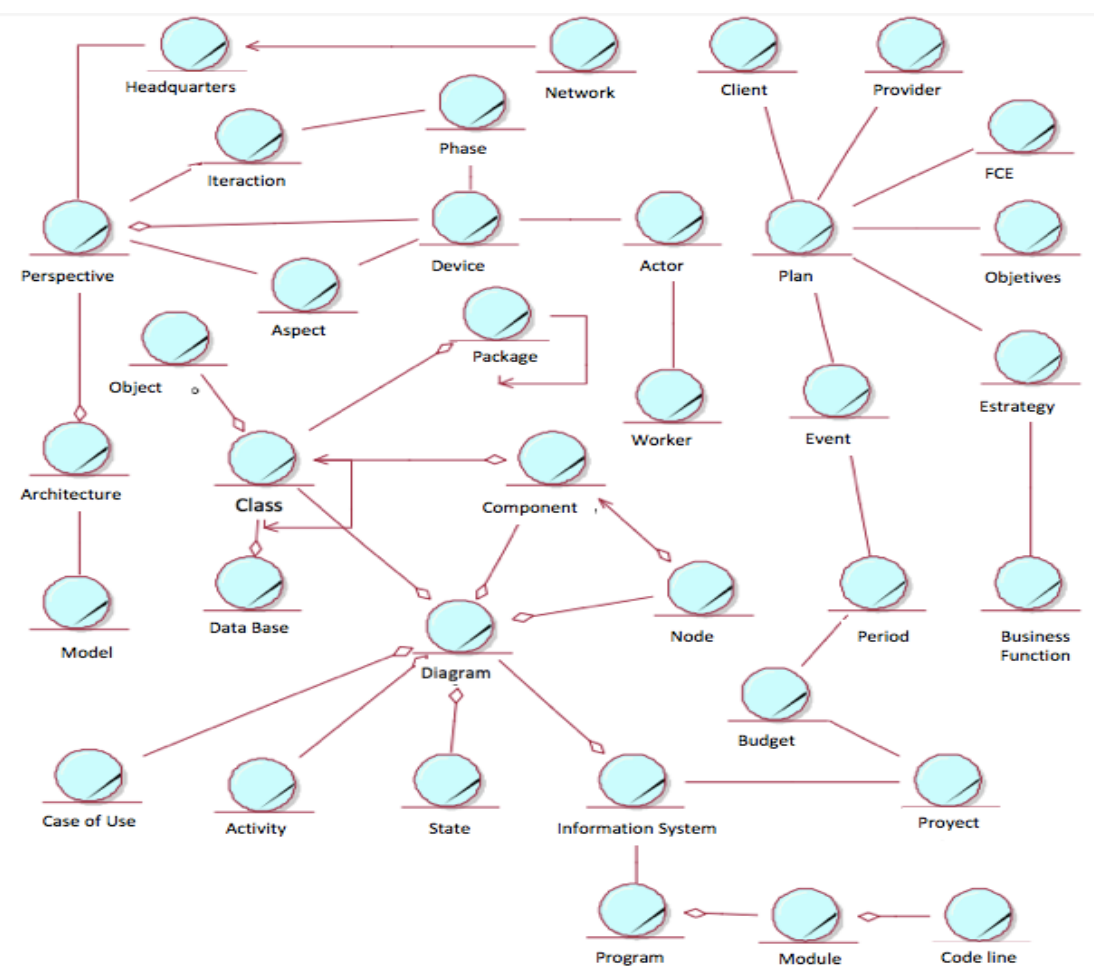

Figure 3. AEU's Logical Metamodel. 
In the Figure 3 appear the main artifacts, models, roles, etc., of the AEU metamodel using Zachaman's framework and in RUP.

\section{RESULTS}

Technically speaking, the experimental test has consisted of applying the performance indicators to randomly selected business processes. First, for the control group, the corresponding metrics were applied through direct observation.

To evaluate the results of the experimental group, an organizational model based on the Unified Enterprise Architecture has been designed. With this tool, it has been possible to integrate all the business processes of an administrative nature, eliminating all the preexisting deficiencies and redundancies. A fundamental aspect that has been established is the articulation of the functionality of the organization with the strategy, that is, the institutional strategic planning (Huapaya et al., 2020). Under these new organizational conditions, the corresponding metrics have been applied to the same selected business processes; for this purpose, the logical model of each process has been built and then its behavior has been simulated by means of the simulation software called Service Model.

\subsection{GROUP CONTROL}

Below is the performance of the process of Preparation of Payrolls, one of the most significant processes of university administrative management. For this purpose, we have observed the duration of each of the activities that make up the process, the errors made, as well as the number of people involved in carrying them out.

\subsubsection{FOR THE EFFICIENCY INDICATOR}

The appropriate index to evaluate the performance of the efficiency indicator is the metric referred to the response time to transactions. In this specific case, it is the duration (in equivalent days) of the execution of the selected processes. 
Table 1. Efficiency in the execution of processes.

\begin{tabular}{|c|c|c|c|c|}
\hline \multirow{2}{*}{$\mathbf{N}^{\circ}$} & \multicolumn{2}{|c|}{ DURATION (days) } & EFFICIENCY \\
\hline 1 & OBSERVED & EXPECTED & $(\%)$ \\
\hline 2 & Process & 85 & 45 & 52.94 \\
\hline 3 & Staff Attendance Control & 16 & 8 & 50.00 \\
\hline 4 & Assessing Staff Performance & 20 & 9 & 45.00 \\
\hline 5 & Service Time Recognition & 45 & 20 & 44.44 \\
\hline 6 & Select Staff & 20 & 10 & 50.00 \\
\hline 7 & Make payments & 15 & 8 & 53.33 \\
\hline $\mathbf{8}$ & Granting Benefits & 35 & 17 & 48.57 \\
\hline 10 & Elaborate Consolidated Remuneration & 12 & 11 & 52.38 \\
\hline 11 & Granting refunds & 30 & 6 & 50.00 \\
\hline 12 & Update Staffing Pattern & 12 & 13 & 43.33 \\
\hline 13 & Issue work certificates & 10 & 6 & 50.00 \\
\hline
\end{tabular}

Average $(\%)=49.78$

Std. deviation $=3.85$

$N^{\prime}=9.6$

As shown in Table 1, the control group is made up of 13 randomly selected processes, which have been measured for the observed duration and the expected duration for the current conditions, i.e. without the application of the IT model based on the enterprise architecture. From the relationship between these two durations, the efficiency of each process has been calculated.

In this regard, the values range between $43.33 \%$ and $57.14 \%$, resulting in an average of $49.78 \%$ that reveals a low system performance. Applying the formula to determine the size of the representative sample, it is established that the number of processes selected for this group is greater (13) than the number required in statistical terms (10). 


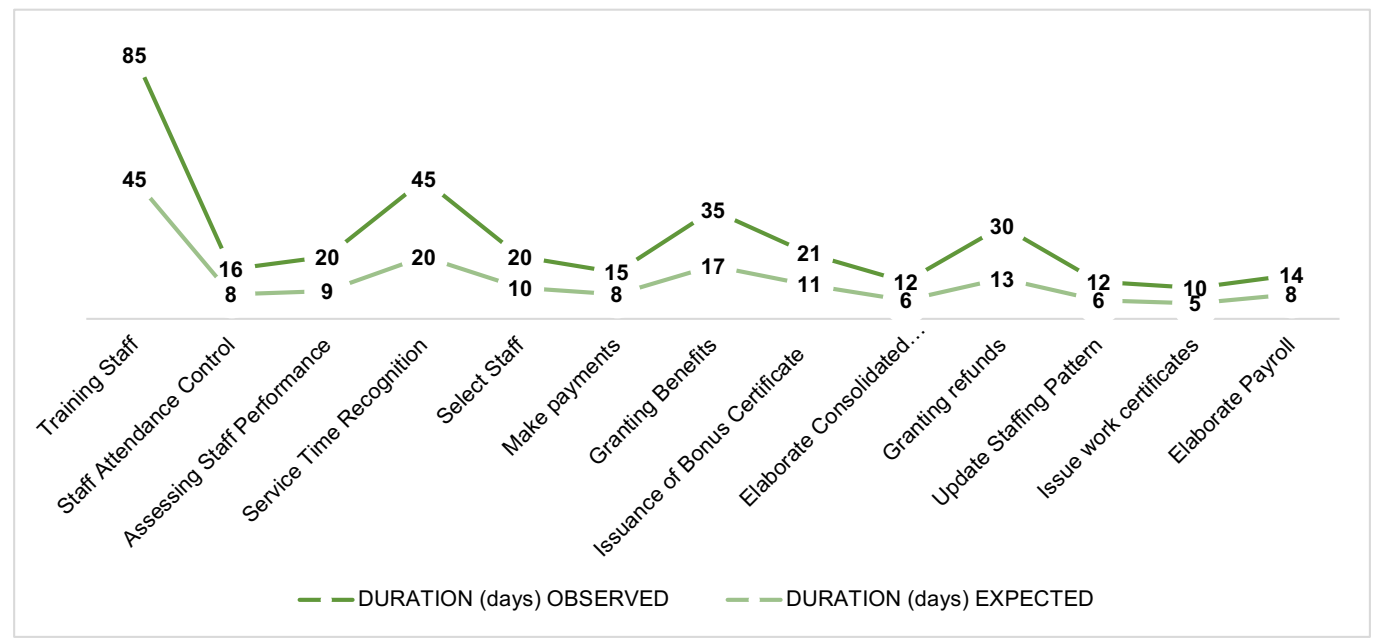

Figure 4. The trend of the results of what is observed and what is expected.

In the Figure 4 show results adequately represent the behavior of the rest of the processes with the observed and expected.

\subsubsection{FOR THE PRODUCTIVITY INDICATOR}

The appropriate index to evaluate the performance of the productivity indicator is the metric referred to the degree of utilization of one of the main resources in the performance of the system's processes, that is, human resources (expressed in the number of transactions carried out per equivalent person-day). In this specific case, for the execution of the processes involved (considering the number of transactions), the number of people involved has been identified, as well as the degree of participation. In this way, the relationship between the number of person-days and the number of transactions carried out by each process is determined.

Table 2 shows the total number of transactions produced for each process. These are the same as those used to evaluate the effectiveness indicator; in terms of the number of people and the degree of participation in carrying out the processes, these have been extracted from the current staff allocation. 
Table 2. Human Resource Productivity for the Control Group.

\begin{tabular}{|c|c|c|c|c|c|c|}
\hline \multirow[b]{2}{*}{$\mathbf{N}^{\circ}$} & \multirow[b]{2}{*}{ PROCESS } & \multirow{2}{*}{$\begin{array}{l}\text { PRODUCTION } \\
\mathrm{N} \text { of transact. }\end{array}$} & \multicolumn{3}{|c|}{ RESOURCES USED } & \multirow{2}{*}{$\begin{array}{c}\text { PRODUCTIVITY } \\
\text { Transac/ } \\
\text { People-days }\end{array}$} \\
\hline & & & People & Participation & People-days & \\
\hline 1 & Training Staff & 200 & 4 & $20 \%$ & 68 & 0.7 \\
\hline 2 & $\begin{array}{l}\text { Staff Attendance } \\
\text { Control }\end{array}$ & 800 & 5 & $40 \%$ & 120 & 6.7 \\
\hline 3 & $\begin{array}{l}\text { Assessing Staff } \\
\text { Performance }\end{array}$ & 50 & 3 & $30 \%$ & 27 & 1.9 \\
\hline 4 & $\begin{array}{l}\text { Service Time } \\
\text { Recognition }\end{array}$ & 20 & 2 & $50 \%$ & 15 & 1.3 \\
\hline 5 & Select Staff & 20 & 2 & $25 \%$ & 10 & 2 \\
\hline 6 & Make payments & 200 & 6 & $30 \%$ & 27 & 7.4 \\
\hline 7 & Granting Benefits & 30 & 2 & $20 \%$ & 14 & 2.1 \\
\hline 8 & $\begin{array}{l}\text { Issuance of Bonus } \\
\text { Certificate }\end{array}$ & 25 & 2 & $60 \%$ & 25.2 & 1 \\
\hline 9 & $\begin{array}{c}\text { Elaborate } \\
\text { Consolidated } \\
\text { Remuneration }\end{array}$ & 20 & 2 & $20 \%$ & 4.8 & 4.2 \\
\hline 10 & Granting refunds & 40 & 3 & $40 \%$ & 18 & 44.4 \\
\hline 11 & $\begin{array}{l}\text { Update Staffing } \\
\text { Pattern }\end{array}$ & 60 & 2 & $40 \%$ & 11.2 & 5.4 \\
\hline 12 & $\begin{array}{l}\text { Issue work } \\
\text { certificates }\end{array}$ & 50 & 2 & $40 \%$ & 48 & 1 \\
\hline 13 & Elaborate Payroll & 550 & 8 & $50 \%$ & 56 & 9.8 \\
\hline
\end{tabular}

Average $(\%)=64.8$

Std. deviation $=11.69$

However, these processes are different in nature, size, frequency, volume and resource requirements; however, in order to evaluate the performance of human resources, it is pertinent to calculate the average productivity of this resource.

Table 2 shows a high variability in personnel productivity, ranging from 0.7 to 44.4 transactions/day_person. The average staff productivity for the system is 6.8 transactions/ day-person.

\subsection{GROUP CONTROL}

For the experimental group, the same procedure applied for the control group has been followed; after having designed the IT model based on the business architecture, the 
duration of each of the activities that make up the payroll process, the errors made, as well as the number of people involved in carrying them out have been observed.

\subsubsection{FOR THE EFFICIENCY INDICATOR}

As for the control group, for the experimental group the appropriate index to evaluate the behavior of the efficiency indicator is the metric referred to the response time to transactions. In this specific case, it is the duration (in equivalent days) of the execution of the selected processes after having applied the enterprise architecture supported by information technology (Ubalde et al., 2020).

The behavior of the selected processes has been simulated (prior modeling). For the purposes of the analysis, the existing gap between the simulated duration and the expected duration under the new conditions has been determined.

Table 3. Efficiency in the execution of the processes Experimental Group.

\begin{tabular}{|c|c|c|c|c|}
\hline \multirow{2}{*}{$\mathbf{N}^{\circ}$} & PROCESS & \multicolumn{2}{|c|}{ DURATION (days) } & EFFICIENCY \\
\hline 1 & THEORICAL & SIMULATED & $(\%)$ \\
\hline 2 & Training Staff & 7 & 6 & 85.71 \\
\hline 3 & Staff Attendance Control & 5 & 5 & 100 \\
\hline 4 & Assessing Staff Performance & 10 & 8 & 80 \\
\hline 5 & Service Time Recognition & 7 & 6 & 85.71 \\
\hline 6 & Select Staff & 7 & 6 & 85.71 \\
\hline 7 & Make payments & 8 & 7 & 87.50 \\
\hline 8 & Granting Benefits & 9 & 8 & 88.89 \\
\hline 9 & Elaborate Consolidated Remuneration & 6 & 7 & 87.50 \\
\hline 10 & Granting refunds & 6 & 5 & 83.33 \\
\hline 11 & Update Staffing Pattern & 2 & 5 & 83.33 \\
\hline 12 & Issue work certificates & 15 & 2 & 100 \\
\hline 13 & Elaborate Payroll & 3.104 & 14 & 93.33 \\
\hline
\end{tabular}

Average $(\%)=89.30$

Std. deviation $=6.83$

$N^{\prime}=10$

As shown in Table 3, the experimental group also consists of 13 randomly selected processes, for which the duration under the conditions of functional redesign, derived from the application of Enterprise Architecture, has been simulated. Likewise, the theoretical 
duration resulting from the assumption of zero interruptions of these processes has been determined. From the relationship between these two durations, the efficiency of each process has been calculated. In this regard, the values range between $80 \%$ and $100 \%$, resulting in an average of $89.30 \%$ that reveals a high performance of the system. Applying the formula for determining the size of the representative sample, it is established that the number of processes selected for this group is greater (13) than the number required in statistical terms (10), which is why these results adequately represent the behavior of the rest of the system's processes.

\subsubsection{FOR THE PRODUCTIVITY INDICATOR}

The appropriate index to evaluate the performance of the productivity indicator is the metric referred to the degree of utilization of one of the main resources in the performance of the system's processes, that is, human resources (expressed in Number of transactions carried out per equivalent person-day). In this specific case, for the execution of the processes involved (considering the number of transactions), the number of people involved has been identified, as well as the degree of participation. In this way, the relationship between the number of person-days and the number of transactions carried out by each process is determined (Pourzolfaghar, Bastidas, \& Helfert, 2019).

Table 4 shows information on the total number of transactions produced for each process, in terms of the number of people involved and the degree of participation in the processes. These have been recalculated based on the impact caused by the functional redesign based on the business architecture supported by information technology.

Table 4. Human resource productivity for the Experimental Group.

\begin{tabular}{|c|c|c|c|c|c|c|}
\hline $\mathbf{N}^{\circ}$ & PROCESS & PRODUCTION & \multicolumn{3}{|c|}{ RESOURCES USED } & PRODUCTIVITY \\
\hline 1 & N of transact. & People & Participation & People-days & $\begin{array}{c}\text { Transac/ } \\
\text { People-days }\end{array}$ \\
\hline 2 & \begin{tabular}{c} 
Training Staff \\
\hline $\begin{array}{c}\text { Staff Attendance } \\
\text { Control }\end{array}$
\end{tabular} & 48 & 2 & $50 \%$ & 17 & 2.82 \\
\hline 3 & $\begin{array}{c}\text { Assessing Staff } \\
\text { Performance }\end{array}$ & 50 & 2 & $40 \%$ & 12 & 66.67 \\
\hline 4 & $\begin{array}{c}\text { Service Time } \\
\text { Recognition }\end{array}$ & 20 & 1 & $30 \%$ & 6 & 8.33 \\
\hline 5 & \begin{tabular}{c} 
Select Staff \\
\hline
\end{tabular} & 20 & 2 & $50 \%$ & 3.5 & 5.71 \\
\hline
\end{tabular}




\begin{tabular}{|c|c|c|c|c|c|c|}
\hline \multirow[b]{2}{*}{$\mathbf{N}^{\circ}$} & \multirow[b]{2}{*}{ PROCESS } & \multirow{2}{*}{$\begin{array}{l}\text { PRODUCTION } \\
\mathrm{N} \text { of transact. }\end{array}$} & \multicolumn{3}{|c|}{ RESOURCES USED } & \multirow{2}{*}{$\begin{array}{c}\text { PRODUCTIVITY } \\
\text { Transacl } \\
\text { People-days }\end{array}$} \\
\hline & & & People & Participation & People-days & \\
\hline 6 & Make payments & 200 & 3 & $30 \%$ & 7.2 & 27.78 \\
\hline 7 & Granting Benefits & 30 & 2 & $20 \%$ & 3.6 & 8.33 \\
\hline 8 & $\begin{array}{c}\text { Issuance of Bonus } \\
\text { Certificate }\end{array}$ & 25 & 1 & $60 \%$ & 4.8 & 5.21 \\
\hline 9 & $\begin{array}{c}\text { Elaborate } \\
\text { Consolidated } \\
\text { Remuneration }\end{array}$ & 20 & 2 & $20 \%$ & 2.4 & 8.33 \\
\hline 10 & Granting refunds & 40 & 2 & $80 \%$ & 9.6 & 83.33 \\
\hline 11 & $\begin{array}{l}\text { Update Staffing } \\
\text { Pattern }\end{array}$ & 60 & 1 & $40 \%$ & 2.8 & 21.43 \\
\hline 12 & $\begin{array}{l}\text { Issue work } \\
\text { certificates }\end{array}$ & 50 & 1 & $40 \%$ & 6 & 8.33 \\
\hline 13 & Elaborate Payroll & 550 & 3 & $40 \%$ & 3.7248 & 147.66 \\
\hline
\end{tabular}

Std. deviation $=43.32$

However, these processes are different in nature, size, frequency, volume and resource requirements; however, in order to evaluate the performance of human resources, it is pertinent to calculate the average productivity of this resource.

Table 4 shows a high variability in personnel productivity, ranging from 2.82 to 147.66 transactions/day_person. The average staff productivity for the system is 30.74 transactions/ day-person.

\section{CONCLUSIONS}

Peruvian universities operate in adverse conditions caused by budgetary limitations, a situation that is evident in low levels of performance, both in the academic and administrative aspects, despite having potentially competitive human resources. One of the main repercussions of these budgetary restrictions is the deficient management of one of the critical success factors, which is information technology in its role as a strategic tool for organizational management. Likewise, an evidence of the deficient handling of the information technology is translated in the nonexistence of some coherent organizational model, that is aligned to the institutional objectives (Massana et al., 2017).

The organizational model based on the Unified Enterprise Architecture (AEU) proposed 
at the prototype level constitutes a valuable alternative for improving the functional competitiveness of the universities that apply it, since it allows such management to harmonize in a systemic manner the business logic with the technical language. AEU is a powerful tool to support the management of organizations. This methodology, when applied in an appropriate way, contributes to improve the performance of the same; on the other hand, it is a valuable support to optimize the performance of the business processes (Yin, 2017).

In relation to the studied reality, the tests carried out have demonstrated that the Unified Enterprise Architecture is an adequate methodology to achieve the objectives set out in this research work, that is, to design a holistic organizational model to influence the administrative and academic functionality of universities. It has been demonstrated that, to complement in a synergic way the capacity and scope of the Zachman framework as an Enterprise Architecture platform, it is possible to apply the Unified Process methodology (UPM). In this way, a valuable combination of object-oriented technology and the systemic approach to organizational management is achieved (Singh, Van Sinderen, \& Wieringa, 2017).

In summary, it is stated that the Unified Enterprise Architecture contributes to improving the functional competitiveness of universities and, in general, to the administrative management of all institutions that apply it. This work has confirmed once again that information technologies, when used with rationality criteria, play a leading role in consistently supporting business plans, becoming one of the main critical factors of success and competitiveness of organizations (Reyes et al., 2019).

\section{REFERENCES}

Bastidas, V., Helfert, M., \& Bezbradica, M. (2018). A requirements framework for the design of smart city reference architectures. In Proceedings of the 51st Hawaï International Conference on System Sciences (HICCS). http:/ / mural.maynoothuniversity.ie/13344/1/ MH_school $\% 20$ of $\% 20$ business_a $\% 20$ requirements.pdf 
Denicolai, S., \& Previtali, P. (2020) Precision Medicine: Implications for value chains and business models in life sciences. Technological Forecasting and Social Change, 151, 119767. https://doi.org/10.1016/j.techfore.2019.119767

Huapaya, H. D., Rodriguez, G., \& Esenarro, D. (2020). Comparative analysis of supervised machine learning algorithms for heart disease detection. 3C Tecnologia. Glosas de innovación aplicadas a la pyme. Edición Especial Tourism and University: Backbone of Peruvian Economy, Abril 2020, 233-247. http://doi.org/10.17993/3ctecno.2020. specialissue 5.233-247

Kitsios, F., \& Kamariotou, M. (2019). Business strategy modelling based on enterprise architecture: a state of the art review. Business Process Management fournal, 25, 606-624. https://doi.org/10.1108/BPMJ-05-2017-0122

Langermeier, M., Saad, C., \& Bauer, B. (2014). A Unified Framework for Enterprise Architecture Analysis. In Proceedings - IEEE International Enterprise Distributed Object Computing Workshop, EDOCW. 227-236. https://doi.org/10.1109/EDOCW.2014.42

Massana, J., Pous, C., Burgas, L., Melendez, J., \& Colomer, J. (2017). Identifying services for short-term load forecasting using data driven models in a Smart City platform. Sustainable Cities and Society, 28, 108-117. https://doi.org/10.1016/j. scs.2016.09.001

Petar, S., Misita, M., Zoran, J., Mladen, M., Vasilije, M., \& Vladimir, B. (2019). Organizational design based on simulation modeling. The International fournal of Advanced Manufacturing Technology, 104. https://doi.org/10.1007/s00170-017-1453-0

Pourzolfaghar, Z., Bastidas, V., \& Helfert, M. (2019), Standardisation of enterprise architecture development for smart cities. Fournal of the Knowledge Economy. https:// doi.org/10.1007/s13132-019-00601-8 
Reyes, A., Rodriguez, G., \& Esenarro, D. (2019). Hyper Converged Systems Applied (HSA) Methodology to Optimize the Process of Technological Renewal in Data Centers. International Fournal of Recent Technology and Engineering (IFRTE), 8(2S11), 4052-4056. https://www.ijrte.org/wp-content/uploads/papers/v8i2S 11 / B15920982S1119.pdf

Singh, P. M., Van Sinderen, M., \& Wieringa, R. (2017). Reference architecture for integration platforms.In 2017 IEEE 21st International Enterprise Distributed Object Computing Conference (EDOC), Quebec City, QC, Canada, pp. 113-122. https://doi. $\mathrm{org} / 10.1109 / \mathrm{EDOC} .2017 .24$

Ubalde, R., Rodriguez, C., Petrlik, I., Esenarro, D., Lezama, P., \& Sotomayor, J. (2020). Quality model for Peruvian microenterprises of a software product Factory. Test Engineering and Management, 83, 13434. http://testmagzine.biz/index.php/ testmagzine/article/view/6062

Yin, R. K. (2017). Case study research and applications: design and methods. Sage publications. 